\title{
Clinical and paraclinical characteristics of patients undergoing hemodialysis
}

\author{
Sanaz Jamshidi ${ }^{\circledR}$, Sepideh Hajian ${ }^{2 *}{ }^{\circledR}$, Nafiseh Rastgoo $^{1}$ \\ ${ }^{1}$ Qazvin University of Medical Sciences, Qazvin, Iran \\ ${ }^{2}$ Department of Nephrology, Velayat Hospital, Qazvin University of Medical Sciences, Qazvin, Iran
}

Correspondence to:

Sepideh Hajian,

Email: s.hajian@qums.ac.ir

Received: 18 Apr. 2021 Accepted: 7 June 2021 ePublished: 12 July 2021

Keywords: Hypertension, Hemodialysis, End-stage renal disease

\begin{abstract}
Introduction: End-stage renal disease (ESRD) is an irreversible decrease in kidney function with severe consequences.

Objectives: The aim of this study was to investigate clinical and paraclinical characteristics of hemodialysis patients.

Patients and Methods: This study was a descriptive-analytical performed on 105 patients undergoing hemodialysis referred to Bou Ali and Velayat hospitals in Qazvin. The data were included age, gender, duration of dialysis, kind of vascular access, kind of catheter, site of catheters, weight, height, systolic and diastolic blood pressure, kind of flux, use of midodrine, kind of dialysis solution, number of dialysis per week, calcium (Ca), iron, total iron binding capacity (TIBC), ferritin, parathyroid hormone (PTH), Kt/N, blood urea nitrogen (BUN) and creatinine (Cr). The data were analyzed using SPSS version 21.

Results: The mean age of the patients was $60.97 \pm 15.13$ years and $44.8 \%$ of the patients were females. The mean number of dialysis per week was 2.84 times with a mean duration of 3.90 years. The mean $\mathrm{Cr}$ level was $8.89 \pm 3.14 \mathrm{mg} / \mathrm{dL}$. Males had higher level of BUN $(55.91 \pm 16.06 \mathrm{mg} / \mathrm{dL}$ versus $65.24 \pm 17.53 \mathrm{mg} /$ $\mathrm{dL}, P=0.006)$ and $\mathrm{Cr}(8.09 \pm 2.43 \mathrm{mg} / \mathrm{dL}$ versus $9.59 \pm 3.47 \mathrm{mg} / \mathrm{dL}, P=0.010)$. Arteriovenous fistula/AVF was the most common vascular access $(76.2 \%$ of cases). With increasing BUN, number of dialysis per week and weight, the level of $\mathrm{Cr}$ increases significantly $(P<0.05)$. In the younger patients, $\mathrm{Cr}$ showed low level compared to the older patients.

Conclusion: The number of dialysis per week, weight and BUN level is factors to predict the level of Cr and with increasing these factors, the level of $\mathrm{Cr}$ increases. The mean $\mathrm{Cr}$ level was high which showed inadequacy of hemodialysis in these patients. The level of $\mathrm{Cr}$ and BUN is higher in men.
\end{abstract}

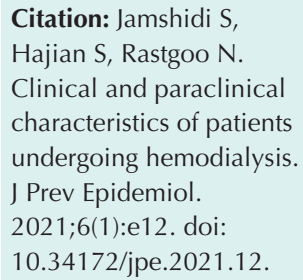

Citation: Jamshidi S Clinical and paraclinica characteristics of patients undergoing hemodialysis. Prev Epidemiol. 10.34172/jpe.2021.12

\section{Introduction}

End-stage renal disease (ESRD) is a severe form of chronic kidney disease (CKD) and an irreversible decrease in kidney function that results in death without dialysis or kidney transplantation (1). In Europe, the annual incidence of ESRD is 171 people per million (2) and in the United States, 336 people per million (3). The incidence of ESRD in the United Kingdom is 100 people per million annually (4). It is estimated that there are currently 1.9 million people with ESRD in the world of which most of them undergo hemodialysis (5). According to statistics, the incidence of ESRD in Iran increased in recent years $(6,7)$.

Diabetes and hypertension are among the risk factors associated with the occurrence of the ESRD (8). Renal replacement therapy is a general term for different methods used in the treatment of renal failure and includes hemodialysis, peritoneal dialysis and kidney allograft transplantation (9). In Iran and

\section{Key point}

Factors like the number of dialysis per week, weight and blood urea nitrogen level can predict the level of creatinine.

many countries, hemodialysis is the most common treatment for the ESRD (10). If ESRD is not treated, it will have significant consequences including hyperkalemia, hypernatremia, increased susceptibility to infection, hypertriglyceridemia, sleep disorder, headache, seizures, muscle cramps, arrhythmia, and nausea and vomiting and itching (11). Long-term complications of dialysis include restless leg syndrome, pruritus, dementia, peritonitis, obesity and electrolyte disorder such as hyperkalemia, hypernatremia, hypernatremia and hypercalcemia (11).

\section{Objectives}

According to the results of some studies, 
dialysis complications are associated with education, age, gender, diabetes and type of dialysis $(12,13)$. The high proportion of patients with renal failure who need dialysis indicates the importance of conducting several studies on the subject. The aim of this study was to investigate clinical and paraclinical characteristics of hemodialysis patients.

\section{Patients and Methods}

Study design

This descriptive study was conducted on hemodialysis patients admitted to Bou Ali and Velayat hospitals in Qazvin, Iran in 2019. Using convenience sampling method, a total of 105 patients undergoing hemodialysis were enrolled in the study. Initially, the research team recorded the data of patients including age, gender, duration of dialysis, kind of vascular access, kind of catheter, site of catheters, weight, height, systolic and diastolic blood pressure, kind of flux, use of midodrine, kind of dialysis solution, number of dialysis per week, calcium (Ca), iron, total iron binding capacity (TIBC), ferritin, parathyroid hormone (PTH), Kt/V, blood urea nitrogen (BUN) and creatinine $(\mathrm{Cr})$.

\section{Ethical issues}

The research followed the tenets of the Declaration of Helsinki. The Ethics Committee of Qazvin University of Medical Sciences approved this study (IR.QUMS. REC.1397.128). The institutional ethical committee at Qazvin University of Medical Sciences approved all study protocols. Accordingly, written informed consent was taken from all participants. This study was extracted from research project at this university (Grant\# 14003170).

\section{Statistical analysis}

SPSS 21 software was used for data analysis. Qualitative variables were described using frequency and percentage and quantitative variables were presented using means and standard deviation. Linear regression and independent $t$ test were used for data analysis. $P$ value less than 0.05 was considered significant.

\section{Results}

In this study, the mean age of the patients was $60.97 \pm 15.13$ years and $44.8 \%$ of the patients $(n=47)$ were females and $55.2 \%(n=58)$ were males. The mean number of dialysis per week was 2.84 times with a mean duration of 3.90 years (Table 1).

The mean Cr level was $8.89 \pm 3.14 \mathrm{mg} / \mathrm{dL}$, which showed inadequacy of hemodialysis in these patients. The mean systolic and diastolic blood pressures were 122.43 \pm 30.224 $\mathrm{mm} \mathrm{Hg}$ and $74.13 \pm 17.851 \mathrm{~mm} \mathrm{Hg}$, respectively. The mean calcium and TIBC were $12.5 \pm 8.52 \mathrm{mg} / \mathrm{dL}$ and $312.02 \pm 153.79 \mu \mathrm{g} / \mathrm{dL}$, respectively (Table 2 ).

Regarding paraclinical characteristic across female and male patients, the results showed that males had higher level of BUN $(55.91 \pm 16.06 \mathrm{mg} / \mathrm{dL}$ versus $65.24 \pm 17.53$ $\mathrm{mg} / \mathrm{dL}, \quad P=0.006)$ and $\mathrm{Cr}(8.09 \pm 2.43 \mathrm{mg} / \mathrm{dL}$ versus $9.59 \pm 3.47 \mathrm{mg} / \mathrm{dL}, P=0.010$ ) (Table 3 ).

The results revealed that AVF was the most common vascular access (76.2\% of cases). Subclavian and jugular site of the catheter had the same percentage in these patients. Regarding kind of flux, there were 68 patients (64.8\%) with high flux in this study. Just five patients were taking midodrine and $94.3 \%$ of the patients used hco3 as solution (Table 4).

Table 1. Clinical characteristics of the patients undergoing hemodialysis

\begin{tabular}{|c|c|c|c|c|}
\hline Variable & Minimum & Maximum & Mean & Standard Deviation \\
\hline Age (year) & 24 & 92 & 60.97 & 15.13 \\
\hline Duration of dialysis (year) & 1 & 19 & 3.90 & 3.15 \\
\hline Weight (kg) & 40 & 135 & 67.15 & 13.88 \\
\hline Height $(\mathrm{cm})$ & 150 & 188 & 164.52 & 7.76 \\
\hline Number of dialysis per week & 1 & 4 & 2.84 & 0.483 \\
\hline
\end{tabular}

Table 2. Para-clinical characteristics of the patients undergoing hemodialysis

\begin{tabular}{|c|c|c|c|c|}
\hline Variable & Minimum & Maximum & Mean & Standard Deviation \\
\hline Calcium (mg/dL) & 4.6 & 12.5 & 8.520 & 1.12 \\
\hline $\operatorname{Iron}(\mu \mathrm{g} / \mathrm{dL})$ & 17 & 885 & 108.31 & 149.84 \\
\hline $\operatorname{TIBC}(\mu \mathrm{g} / \mathrm{dL})$ & 52 & 1001 & 312.02 & 153.79 \\
\hline Ferritin $(\mathrm{ng} / \mathrm{mL})$ & 14 & 1771 & 597.18 & 318.31 \\
\hline PTH (pg/mL) & 16 & 909 & 359.77 & 238.47 \\
\hline $\mathrm{KtV}$ & .64 & 1.70 & 1.19 & 0.22 \\
\hline BUN (mg/dL) & 18 & 108 & 61.06 & 17.44 \\
\hline $\mathrm{Cr}(\mathrm{mg} / \mathrm{dL})$ & 2.4 & 24.0 & 8.891 & 3.1422 \\
\hline Systolic blood pressure $(\mathrm{mm} \mathrm{Hg})$ & 60 & 170 & 122.43 & 30.224 \\
\hline Diastolic blood pressure (mm Hg) & 20 & 100 & 74.13 & 17.851 \\
\hline
\end{tabular}


Table 3. Para-clinical characteristics of the patients undergoing hemodialysis across both genders

\begin{tabular}{|c|c|c|c|c|c|}
\hline Para-clinical variables & & Mean & Standard Deviation & $t$ & $P$ value \\
\hline \multirow{2}{*}{ Calcium (mg/dL) } & Female & 8.70 & 0.92 & \multirow{2}{*}{1.507} & \multirow{2}{*}{0.135} \\
\hline & Male & 8.37 & 1.24 & & \\
\hline \multirow{2}{*}{ Iron $(\mu \mathrm{g} / \mathrm{dL})$} & Female & 110.55 & 139.78 & \multirow{2}{*}{0.137} & \multirow{2}{*}{0.891} \\
\hline & Male & 106.50 & 158.72 & & \\
\hline \multirow{2}{*}{ TIBC $(\mu \mathrm{g} / \mathrm{dL})$} & Female & 311.72 & 152.51 & \multirow{2}{*}{-.018} & \multirow{2}{*}{0.986} \\
\hline & Male & 312.26 & 156.15 & & \\
\hline \multirow{2}{*}{ Ferritin hormone $(\mathrm{ng} / \mathrm{mL})$} & Female & 662.55 & 355.79 & \multirow{2}{*}{1.919} & \multirow{2}{*}{0.058} \\
\hline & Male & 544.21 & 276.28 & & \\
\hline \multirow{2}{*}{ PTH $(p g / m L)$} & Female & 379.70 & 237.81 & \multirow{2}{*}{0.769} & \multirow{2}{*}{0.443} \\
\hline & Male & 343.62 & 239.84 & & \\
\hline \multirow{2}{*}{ KtV } & Female & 1.20 & 0.22 & \multirow{2}{*}{0.630} & \multirow{2}{*}{0.530} \\
\hline & Male & 1.18 & 0.22 & & \\
\hline \multirow{2}{*}{$\mathrm{BUN}(\mathrm{mg} / \mathrm{dL})$} & Female & 55.91 & 16.06 & \multirow{2}{*}{-2.815} & \multirow{2}{*}{0.006} \\
\hline & Male & 65.24 & 17.53 & & \\
\hline \multirow{2}{*}{$\mathrm{Cr}(\mathrm{mg} / \mathrm{dL})$} & Female & 8.01 & 2.43 & \multirow{2}{*}{-2.635} & \multirow{2}{*}{0.010} \\
\hline & Male & 9.59 & 3.47 & & \\
\hline
\end{tabular}

Linear regression showed that by increasing BUN, number of dialysis per week and weight, the level of $\mathrm{Cr}$ increases significantly $(P<0.05)$. In the younger patients, Cr showed low level compared to the older patients (Table 5).

\section{Discussion}

ESRD hazards all aspects of life in patients with CKD. We conducted a study to determine some clinical and paraclinical features of the patients undergoing hemodialysis referred to Bou Ali and Velayat hospitals in Qazvin. In summary, our results indicated that AVF was the most common method for vascular access. The level of $\mathrm{Cr}$ was higher in younger patients. Furthermore, BUN, number of dialysis per week and weight, were predictor of the level of Cr. Males had higher level of BUN and Cr. Most of the patients were men.

Table 4. Dialysis-related factors in the patients undergoing hemodialysis

\begin{tabular}{llcc}
\hline Variable & & No. & $\%$ \\
\hline \multirow{3}{*}{ Kind of vascular access } & Arteriovenous fistula/AVF & 80 & 76.2 \\
& Graft & 1 & 1.0 \\
& Catheter & 24 & 22.9 \\
\hline \multirow{3}{*}{ Kind of catheter } & None & 83 & 79 \\
& Continuous & 17 & 16.2 \\
& Temporary & 5 & 4.8 \\
\hline \multirow{3}{*}{ Site of catheter } & None & 81 & 77.1 \\
& Subclavian & 10 & 9.5 \\
& Femoral & 4 & 3.8 \\
Kind of flux & Jugular & 10 & 9.5 \\
\hline \multirow{2}{*}{ Use of midodrine } & Low & 37 & 35.2 \\
& High & 68 & 64.8 \\
\hline \multirow{2}{*}{ Kind of solution } & No & 100 & 95.2 \\
\cline { 2 - 4 } Hypotension in home & Yes & 5 & 4.8 \\
\hline & Hco3 & 99 & 94.3 \\
& Acetate & 6 & 5.7 \\
\hline
\end{tabular}

Hesari et al conducted a study to compare the serum levels of hormones and various biochemical parameters in the patients undergoing hemodialysis. From all patients, one blood sample before and one sample immediately after hemodialysis to measure T3, T4, free triiodothyronine (FT3), thyroid stimulating hormone, free thyroxine (FT4) and cholesterol, triglyceride, BUN, uric acid and fasting blood sugar (FBS) were taken. The results showed that the levels of FT3, FT4, and T3 had a significant increase

Table 5. Linear regression to predict the level of $\mathrm{Cr}$

\begin{tabular}{|c|c|c|c|c|}
\hline \multirow[t]{2}{*}{ Variable } & \multicolumn{2}{|c|}{$\begin{array}{l}\text { Unstandardized } \\
\text { Coefficients }\end{array}$} & \multirow{2}{*}{$\begin{array}{c}\begin{array}{c}\text { Standardized } \\
\text { Coefficients }\end{array} \\
\text { Beta } \\
\end{array}$} & \multirow[t]{2}{*}{$P$ value } \\
\hline & B & SE & & \\
\hline Gender & 1.381 & 0.709 & 0.220 & 0.055 \\
\hline Duration of dialysis (year) & 0.055 & 0.090 & 0.055 & 0.544 \\
\hline Kind of vascular access & -1.096 & 0.884 & -0.295 & 0.218 \\
\hline Kind of catheter & 0.867 & 1.099 & 0.148 & 0.433 \\
\hline Site of catheters & -0.158 & 0.669 & -0.048 & 0.813 \\
\hline Weight (kg) & 0.050 & 0.024 & 0.221 & 0.043 \\
\hline Height $(\mathrm{cm})$ & -0.046 & 0.046 & -0.114 & 0.324 \\
\hline Hypotension in home & 0.438 & 1.064 & 0.043 & 0.682 \\
\hline Kind of flux & -0.147 & 0.759 & -0.022 & 0.847 \\
\hline Use of midodrine & 0.512 & 1.559 & 0.035 & 0.743 \\
\hline Number of dialysis per week & 1.725 & 0.641 & 0.265 & 0.009 \\
\hline Calcium (mg/dL) & -0.317 & 0.270 & -0.113 & 0.243 \\
\hline Iron $(\mu \mathrm{g} / \mathrm{dL})$ & 0.001 & 0.004 & 0.029 & 0.879 \\
\hline $\mathrm{TIBC}(\mu \mathrm{g} / \mathrm{dL})$ & -0.001 & 0.003 & -0.030 & 0.860 \\
\hline Ferritin $(\mathrm{ng} / \mathrm{mL})$ & 0.000 & 0.001 & -0.038 & 0.675 \\
\hline PTH (pg/mL) & 0.002 & 0.001 & 0.131 & 0.158 \\
\hline $\mathrm{Kt} / \mathrm{V}$ & -1.450 & 1.411 & -0.104 & 0.307 \\
\hline $\mathrm{BUN}(\mathrm{mg} / \mathrm{dL})$ & 0.040 & 0.017 & 0.220 & 0.024 \\
\hline $\begin{array}{l}\text { Systolic blood pressure }(\mathrm{mm} \\
\mathrm{Hg})\end{array}$ & -0.010 & 0.020 & -0.095 & 0.618 \\
\hline $\begin{array}{l}\text { Diastolic blood pressure }(\mathrm{mm} \\
\mathrm{Hg})\end{array}$ & -0.007 & 0.032 & -0.038 & 0.834 \\
\hline Age (year) & -0.046 & 0.020 & -0.222 & 0.021 \\
\hline
\end{tabular}


after hemodialysis. Cr, BUN and uric acid levels decreased following hemodialysis. However, cholesterol, triglyceride and FBS levels showed a significant increase. Dialysis can improve and increase the level of thyroid hormones in patients with renal failure. Hemodialysis, on the other hand, increases total cholesterol and triglycerides, and as a result, can increase the risk of cardiovascular disease (14). In dialysis patients, blood uric acid levels increase due to decreased clearance (15). Our study showed that ESRD caused high level of BUN. Serum levels of BUN and Cr decrease significantly after hemodialysis compared to before hemodialysis; however these factors are in high level (16). Alsaran et al (16) reported that FT3 and FT4 levels had increased significantly in the last three months after hemodialysis compared to before hemodialysis. However, TSH levels did not show a statistically significant difference before and after hemodialysis (17). In this study, the mean blood pressure was in the normal range. In a study by Rocco et al, $64.9 \%$ of hemodialysis patients had high blood pressure and $54.4 \%$ of patients had controlled blood pressure, of which $35.1 \%$ did not receive antihypertensive drugs and $20.6 \%$ of them received antihypertensive medication (18). Indeed the control of hypertension is depends on many factors such as drugs used to treat and lifestyle of the patients, therefore it cannot be compared exactly.

In a study, serum urea level was more than $200 \mathrm{mg} /$ dL but following dialysis, $66 \%$ of the patients had urea level less than $200 \mathrm{mg} / \mathrm{dL}$. Regarding Cr, most of the patients had $\mathrm{Cr}$ between 7-12 mg/dL before dialysis, while following dialysis the $\mathrm{Cr}$ level was decreased to $<7 \mathrm{mg}$ / dL (19). It shows that the level of $\mathrm{Cr}$ even in the patients undergoing hemodialysis is high and just hemodialysis it decreases a little.

\section{Conclusion}

According to the results, the number of dialysis per week, weight and BUN level are factors to predict the level of $\mathrm{Cr}$ and with increasing these factors, the level of $\mathrm{Cr}$ increases. The mean Cr level was high which showed inadequacy of hemodialysis in these patients. The level of $\mathrm{Cr}$ and BUN is higher in men.

\section{Limitations of the study}

Our major limitation in this research was small sample size. In the cross-sectional studies, due to confounding bias, it is suggested to select as large as possible sample size.

\section{Authors' contribution}

$\mathrm{SH}, \mathrm{NR}$ and SJ were the principal investigators in the research and prepared the concept and design of this study. All authors reviewed the manuscript before submission and approved the content of the manuscript.

\section{Conflict of interest}

There is no conflict of interest in this research.

\section{Ethical considerations}

Ethical issues (including plagiarism, data fabrication, double publication) have been completely observed by the authors.

\section{Funding/Support}

This research was granted by Qazvin University of Medical Sciences (Grant \#14003170).

\section{References}

1. Bond M, Pitt M, Akoh J, Moxham T, Hoyle M, Anderson R. The effectiveness and cost- effectiveness of methods of storing donated kidneys from deceased donors: a systematic review and economic model. Health Technol Assess. 2009; 13:1-156. doi: 10.3310/hta13380.

2. Meguid El Nahas A, Bello AK. Chronic kidney disease: the global challenge. Lancet. 2005;365:331-40. doi: 10.1016/ S0140-6736(05)17789-7.

3. United States Renal Data System: Annual data report: incidence and prevalence of ESRD (2003). Am J Kidney Dis. 2003;42:S37-S173.

4. Ansell D, Feest T, eds. UK renal registry report 2004. Bristol: UK Renal Registry; 2004.

5. Jürgensen JS, Arns W, Hass B. Cost- effectiveness of immunosuppressive regimens in renal transplant recipients in Germany: a model approach. Eur J Health Econ. 2010;11:1525. doi: 10.1007/s10198-009-0148-3.

6. Grassmann A, Gioberge S, Moeller S, Brown G. ESRD patients in 2004: global overview of patient numbers, treatment modalities and associated trends. Nephrol Dial Transplant. 2005;20:2587-93. doi: 10.1093/ndt/gfi159.

7. Barsoum RS. End-stage renal disease in the developing world. Artif Organs. 2002;26:735-6. doi: 10.1046/j.15251594.2002.00916.x

8. Easterling RE. Racial Factors in the Incidence and Causation of End-Stage Renal Disease (ESRD). Trans Am Soc Artif Intern Organs. 1977;23:28-32. doi: 10.1097/00002480-19770023000008.

9. U.S Department of Health and Human Services. National Instute of Health, National Kidney and Urologic diseases Information Clearinghouse. Treatment Methods for Kidney Failure Peritoneal Dialysis. National Instiute of Diabetes and Digestive and Kidney Diseases. NIH Publication No.06-4688 May 2006. Available at: https://www.niddk.nih.gov/.

10. Zhang Q-L, Rothenbacher D. Prevalence of chronic kidney disease in population-base d studies: systematic review. BMC Public Health. 2008;8:117. doi: 10.1186/1471-2458-8-117.

11. Braunwald A, Fauci AS, Kasper DL, Hauser SL, Longo DL, Jameson JL, eds. Harrison's Principles of Internal Medicine, 15th edn. New York: McGraw-Hill; 2001:1974-9.

12. Alashek WA, Mclntyre CW, Taal MW. Epidemiology and aetiology of dialysis-treated end-stage kidney disease in Libya. BMC Nephrol. 2012;13:1-7. doi: 10.1186/1471-2369-13-33

13. Aslam N, Bernardini J, Fried L, Burr R, Piraino B. Comparison of infectious complications between incident hemodialysis and peritoneal dialysis patients. Clin J Am Soc Nephrol. 2006;1:1226-33. doi: 10.2215/CJN.01230406.

14. Hesari Z, Mansourian A, Ghasempour G, Ahmadi A. Assessing the changes in some biochemical parameters in hemodialysis patients before and after hemodialysis, in 5 Azar Hospital of Gorgan. Razi J Med Sci. 2018;25:84-9.

15. Zawada AM, Carrero JJ, Wolf M, Feuersenger A, Stuard S, Gauly A, et al. Serum uric acid and mortality risk among hemodialysis patients. Kidney Int Rep. 2020;5:1196-206. doi: 
10.1016/j.ekir.2020.05.021

16. Shamsadini S, Darvish MS, Abdollahi H, Fekri AR, Ebrahimi HA. Creatinine, blood urea nitrogen and thyroid hormone levels before and after haemodialysis. East Mediterra Health J. 2006;12: 231-5.

17. Alsaran K, Sabry A, Alshahhat H, Babgy E, Alzahrani F. Free thyroxine, free triiodothyronine and thyroid-stimulating hormone before and after hemodialysis in Saudi patients with end-stage renal disease: Is there any difference? Saudi J Kidney
Dis Transplan; 2011;22:917

18. Rocco MV, Yan G, Heyka RJ, Benz R, Cheung AK. Risk factors for hypertension in chronic hemodialysis patients: baseline data from the HEMO study. Am J Nephrol. 2001;21:280-8. doi: $10.1159 / 000046262$.

19. Amin N, Mahmood RT, Asad MJ, Zafar M, Raja AM. Evaluating urea and creatinine levels in chronic renal failure pre and post dialysis: a prospective study. J Cardiovasc Dis. 2014;22:1-4. 